\title{
Correction: Development of experimental GBS vaccine for mucosal immunization
}

The PLOS ONE Staff

There is an error in Table 1. Sections within nucleotide sequences from primers A1, D1, and D2 should be bolded. The publisher apologizes for the error. Please see the corrected Table 1 here.

\section{Gopenaccess}

Citation: The PLOS ONEStaff (2018) Correction: Development of experimental $\mathrm{GBS}$ vaccine for mucosal immunization. PLOS ONE 13(6): e0198577. https://doi.org/10.1371/journal. pone.0198577

Published: June 1, 2018

Copyright: @ 2018 The PLOS ONE Staff. This is an open access article distributed under the terms of the Creative Commons Attribution License, which permits unrestricted use, distribution, and reproduction in any medium, provided the original author and source are credited. 
Table 1. Oligonucleotide primers.

\begin{tabular}{|c|c|c|}
\hline Primers & Direction & Nucleotide sequence from 5' to 3 ' \\
\hline A1 & forward & GGGGTACCCCCGATGAGAGCAGCTGGTATTG \\
\hline $\mathrm{B} 1$ & reverse & CAGAATCATTTGTTTCATCAAACAATGCGCCATCATAGTTT \\
\hline $\mathrm{C} 1$ & forward & TGGAGCAGGTTGAGAAGGAAGGTTCTGCGCGAGTGATAGAT \\
\hline D1 & reverse & CAACAAGCTTCAAAGCATCGTTGG \\
\hline E1 & forward & TTGATGAAACAAATGATTCTGATG \\
\hline F1 & reverse & TTCCTTCTCAACCTGCTCCA \\
\hline$\underline{\mathrm{D} 2}$ & reverse & CAACAGGATCCAAAGCATCGTTGG \\
\hline $\mathrm{B} 2$ & forward & TGAGTGAACCACAGCCAGAA \\
\hline B3 & forward & TCAGCAACGTGTGTCTTGGT \\
\hline B4 & reverse & CGAACCTTTACTTCGGCATC \\
\hline B5 & reverse & GTGATTCCCTTTGCTCTGC \\
\hline
\end{tabular}

The bold sections in the nucleotide sequences indicate the sites of restriction endonucleases used to create the design.

https://doi.org/10.1371/journal.pone.0198577.t001

\section{Reference}

1. Gupalova T, Leontieva G, Kramskaya T, Grabovskaya K, Bormotova E, Korjevski D, et al. (2018) Development of experimental GBS vaccine for mucosal immunization. PLoS ONE 13(5): e0196564. https:// doi.org/10.1371/journal.pone.0196564 PMID: 29727446 